\title{
Danos e potencial reprodutivo de Pratylenchus brachyurus em cinco espécies vegetais
}

\author{
Janile Tamiozzo Mainardi ${ }^{1}$, Guilherme Lafourcade Asmus ${ }^{2}$ \\ ${ }^{1}$ Universidade Estadual de Mato Grosso do Sul, Unidade Universitária de Aquidauana, Aquidauana, Mato Grosso do Sul, Brasil. \\ E-mail: janile_mainardi@yahoo.com.br \\ ${ }^{2}$ Empresa Brasileira de Pesquisa Agropecuária, Centro de Pesquisa Agropecuária do Oeste, Dourados, Mato Grosso do Sul, Brasil. \\ E-mail: guilherme.asmus@embrapa.br
}

Recebido: 01/10/2015; Aceito: 15/12/2015.

\section{RESUMO}

O nematoide Pratylenchus brachyurus tem se destacado como a espécie de nematoide fitoparasita mais frequente em áreas de produção agrícola do Brasil-Central. A reação de espécies vegetais ao nematoide tem sido pouco estudada. Por essa razão, foram realizados dois experimentos em casa de vegetação, com o objetivo de caracterizar a reação de cinco espécies vegetais de interesse econômico (soja, algodoeiro, milho, capim-marandú e capimmombaça) à presença de $P$. brachyurus. Cada espécie foi inoculada com zero, 333, 1.000, 3.000 e 9.000 nematoides/planta no primeiro experimento e zero, 1.500, 4.500, 13.500 e 40.500 nematoides/planta no segundo experimento. Sessenta dias após a inoculação, foram realizadas avaliações morfo-fisiológicas das espécies vegetais (altura de planta, teor de clorofila e taxa fotossintética) e aos 90 dias após a inoculação avaliou-se a massa fresca do sistema radicular, a massa seca total da parte aérea, o número de lesões no sistema radicular, determinando o número de ovos/g de raiz e o fator de reprodução do nematoide. O nematoide causou danos primários, caracterizados por lesões radiculares em todas as espécies, mas com maior intensidade na soja. No entanto, independente da densidade populacional, não se verificou danos na parte aérea. A multiplicação do nematoide, expressa pelo fator de reprodução (FR) foi maior na menor densidade populacional, em ambos os experimentos. Milho e soja são as espécies que permitem a maior multiplicação de $P$. brachyurus em suas raízes.

Palavras-chave: Glycine max, Gossypium hirsutum, Zea mays, Brachiaria brizantha, Panicum maximum.

\section{Damage and reproductive potential Pratylenchus brachyurus on five selected plant species}

\begin{abstract}
Pratylenchus brachyurus is a very important plant-parasitic-nematode to agricultural crops in Brazil, due to its high incidence and widespread dissemination. The response of plant species to P. brachyurus has been poorly studied. For this reason, two experiments were carried out in a greenhouse, with the aim of characterizing the response of five selected plant species of economic importance (soybean, cotton, maize, marandu grass, and mombaça grass) to five population densities of $P$. brachyurus. Each specie was inoculated with zero; 333; 1,000; 3,000 and 9,000 nematodes per plant in the first experiment and zero, 1,500; 4,500; 13,500 and 40,500 nematodes per plant in the second experiment. Sixty days after inoculation, morphological and physiological traits (plant height, chlorophyll content and photosynthetic rate) were assessed. At 90 days after inoculation, the fresh root matter, shoot dry matter, and number of lesions on the root system were evaluated, and the number of eggs per gram root and nematode reproduction factor were determined. Primary damage (root lesions) caused by nematodes occurred in all plant species, but were more severe on soybean crop. However, regardless of population density, there was no damage to shoots, which characterizes the low aggressiveness of $P$. brachyurus to tested plant species. The multiplication of the nematode, expressed by the reproduction factor (RF), was higher in the lowest population densities in both experiments. Reproduction of the nematode was higher on maize and soybean roots.
\end{abstract}

Key words: Glycine max, Gossypium hirsutum, Zea mays, Brachiaria brizantha, Panicum maximum. 


\section{Introdução}

O nematoide das lesões radiculares, Pratylenchus Filipjev, 1936, é um dos principais nematoides em diversas culturas no mundo (SASSER; FRECKMAN, 1987). No Brasil, P. brachyurus (Godfrey) Filipjev and Schuurmans Stekhoven, 1941, tem se destacado como a espécie mais frequente em áreas de produção de soja e algodão do cerrado brasileiro (ABREU; AGNES, 2015; RIBEIRO et al., 2010; SILVA et al., 2004). Sua alta frequência está associada ao cultivo sucessivo de variedades suscetíveis de soja bem como a mudança de exploração do solo na entressafra, muitas das vezes semeado com culturas conhecidas como boas hospedeiras, tais como milho ou algodoeiro (DIAS et al., 2010).

Os principais sistemas de produção no Brasil Central são baseados no cultivo de soja, milho ou algodão. Destas, algodão e milho podem ser semeados na primavera/verão (culturas de verão) ou após a soja, denominada cultura de segunda safra, ou safrinha. No que diz respeito à pecuária, as principais espécies forrageiras em uso no Brasil são o capim-marandu (Brachiaria brizantha Hochst. ex A. Rich. 'Marandu') e o capim-mombaça (Panicum maximum Jacq. 'Mombaça'). Eventualmente, essas forrageiras podem ser cultivadas em sequência à soja, ao milho ou ao algodão, em sistemas integrados lavoura-pecuária (ILP) ou para a formação de cobertura vegetal no sistema plantio direto. No entanto, dependendo da suscetibilidade das forrageiras esta prática pode trazer consequências indesejáveis ao contribuir para o aumento da população do nematoide na cultura principal semeada em sequência.

Populações elevadas de $P$. brachyurus em raízes de soja e algodoeiro são frequentes e, em algumas situações, há redução da produtividade da soja em até 30\%. (RIBEIRO et al., 2010; SILVA et al., 2004). A reprodução de $P$. brachyurus em soja, milho, algodão, capim-braquiária e capim-colonião já foi documentada (INOMOTO, 2011; INOMOTO et al., 2007; LINSEY; CAIRNS, 1971; MACHADO et al., 2007). No entanto, sua capacidade de causar danos, como agente primário, ainda é tema de discussão (CARVALHO et al., 2013; MACHADO et al., 2006).

Assim, objetivou-se com este trabalho avaliar os danos e o potencial reprodutivo de diferentes densidades populacionais de $P$. brachyurus em algumas espécies vegetais de importância econômica, tais como: soja (Glycine $\max$ (L.) Merr. 'Anta 82RR'), algodão (Gossypium hirsutum L. 'Fibermax 966'), milho (Zea mays L. 'BRS 1010'), capim-marandu (Brachiaria brizantha Hochst. ex A. Rich. 'Marandu') e capimmombaça (Panicum maximum Jacq. 'Mombaça').

\section{Material e Métodos}

Foram realizados dois experimentos, em casa de vegetação da Embrapa Agropecuária Oeste, em Dourados - MS, no período de abril a novembro de 2012, que diferiram apenas quanto às densidade populacional iniciais do nematoide utilizado e à época. O primeiro experimento foi conduzido nos meses de abril a julho (temperatura média na casa-de-vegetação de $20,5{ }^{\circ} \mathrm{C}$ ) utilizando-se a densidade populacional inicial do nematoide (Pi) de zero, 333, 1.000, 3.000 e 9.000 espécimes/planta. O segundo foi conduzido nos meses de agosto a novembro (temperatura média na casa-de-vegetação de $24,0^{\circ} \mathrm{C}$ ) utilizando-se a densidade populacional de zero, $1.500,4.500,13.500$ e 40.500 espécimes/planta. A população de $P$. brachyurus utilizada foi obtida de raízes de soja, no município de Chapadão do Sul, MS, e multiplicada em quiabeiro (Abelmoschus esculentus L.). Para extração dos nematoides das raízes de quiabeiro foi utilizada a técnica de Coolen e D’Herde (1972).

Os experimentos foram instalados em delineamento experimental inteiramente casualizado, com oito repetições, em esquema fatorial 5 x 5 , sendo cinco espécies vegetais: soja 'Anta 82RR', algodão 'Fibermax 966', milho 'BRS 1010', capim-marandu e capimmombaça, e cinco densidades populacionais de $P$. brachyurus. Cada parcela experimental foi constituída por um vaso contendo uma planta.

O substrato para plantio (65\% areia, $7 \%$ silte e $28 \%$ argila) foi desinfestado por solarização durante sete dias (GHINI, 2004) e acondicionado em copos plásticos com capacidade para $400 \mathrm{ml}$. Foram semeadas três sementes da mesma espécie por copo e após sete dias de emergência das plântulas efetuou-se o desbaste deixando-se uma planta por copo. Dois dias após, os copos contendo as mudas foram transferidos para o laboratório, onde foi realizada a inoculação.

A inoculação foi realizada depositando-se $5 \mathrm{~mL}$ da suspensão aquosa contendo os nematoides, em dois orifícios no solo, a 2,5 cm de profundidade, e a $1 \mathrm{~cm}$ do colo das plantas. Após o procedimento as mudas permaneceram no laboratório por quatro dias, sendo então transferidas para a casa de vegetação e transplantadas para vasos de cerâmica contendo 3 litros de substrato idêntico ao utilizado nos copos e adubado com fertilizante granulado (1,0 g de NPK, de fórmula 20-20-20/copo). O transplante foi realizado transferindo-se o torrão indeformado de substrato de cada copo, contendo uma muda, para um orifício no substrato contido nos vasos que a partir de então foram mantidos em casa de vegetação durante todo o período experimental. O substrato foi irrigado duas vezes ao dia.

Aos 60 dias após a inoculação foram realizadas as avaliações destinadas a determinar os efeitos 
decorrentes do parasitismo de $P$. brachyurus sobre os componentes morfo-fisiológicos das espécies vegetais (altura de planta, teor de clorofila e taxa fotossintética). Aos 90 dias após inoculação, quando as espécies vegetais se encontravam no estágio reprodutivo avaliouse a massa fresca do sistema radicular, a massa seca total da parte aérea, o número de lesões no sistema radicular e determinou-se o número de ovos/g de raiz e o fator de reprodução. Nas espécies de folhas largas (algodão e soja) mediu-se a altura de plantas; nas gramíneas mediu-se a altura da base até a ponta da folha mais comprida. Para o teor de clorofila utilizou-se o medidor eletrônico Falker, modelo CFL1030 e as medições foram realizadas na segunda e terceira folhas completamente desenvolvidas a partir da extremidade superior. Foram utilizados os dados médios das duas medições. A fotossíntese foi medida com o analisador de gases no infravermelho (IRGA) ADC BioScientific Ltd, modelo LCA Pro+, no período da manhã, na segunda e terceira folhas completamente desenvolvidas.

Para avaliação da massa seca da parte aérea, os colmos e hastes foram cortados a $0,5 \mathrm{~cm}$ acima do nível do solo e a parte aérea foi acondicionada em saco de papel, com perfurações nas laterais, para secagem em estufa de circulação forçada de ar, a $60^{\circ} \mathrm{C}$ por sete dias, quando o peso da massa seca atingiu valor constante. Os sistemas radiculares foram cuidadosamente retirados dos vasos e lavados em água corrente para retirada do substrato aderido. As raízes foram secas ao ar sobre papel absorvente por cerca de 20 minutos para retirada do excesso de água e pesadas individualmente.Em seguida realizou-se o peso do sistema radicular fresco; as raízes foram avaliadas visualmente quanto à presença e intensidade de lesões causadas pelo nematoide. Para a avaliação foi proposta a escala a seguir: 1 - ausência de lesões; 2 - lesões leves (até $25 \%$ de tecido lesionado); 3 - lesões moderadas (26 a $50 \%$ de tecido lesionado); 4 lesões severas (51 a $75 \%$ de tecido lesionado); 5 lesões muito severas (75 a $100 \%$ de tecido lesionado).

Para a avaliação da reprodução, os nematoides foram extraídos das raízes pelo método proposto por Coolen e D'Herde (1972), inativados em banho-maria à $57^{\circ} \mathrm{C}$ por 5 minutos e mantidos sob refrigeração por 24 horas, para a sedimentação e concentração na suspensão. A quantificação dos espécimes foi feita em lâmina de Peters em microscópio óptico modelo HBO 50. Foram estimadas as populações finais de $P$. brachyurus nas raízes (Pf), o número de nematoides por grama de raiz (NGR) e calculado o fator de reprodução $(\mathrm{FR}=\mathrm{Pf} / \mathrm{Pi})$, conforme Oostenbrink (1966).

Os dados foram analisados quanto à homogeneidade de variância pelo Teste de Cochran e transformados em $\sqrt{x+0,5}$ quando necessário. Quando houve efeito significativo nos fatores quantitativos (densidade de inóculo) fez-se a análise de regressão.
Os fatores qualitativos (espécies vegetais) foram submetidos a testes de comparação múltipla de médias. Utilizou-se o aplicativo SAEG 5.0 (Sistema para Análises Estatísticas, UFV, 1992) para a análise de variância e testes de médias, e o programa Sisvar para a análise de regressão. As figuras contendo as regressões foram elaboradas com o programa Excel.

\section{Resultados e Discussão}

Não houve efeito significativo da densidade populacional de $P$. brachyurus sobre: a altura das plantas, a massa seca da parte aérea, a massa fresca da raiz, o teor de clorofila e a taxa fotossintética das diferentes espécies vegetais. Tampouco houve interação entre espécies vegetais e o nível populacional do nematoide (Tabelas 1, 2 e 3) para essas variáveis.

As diferenças significativas detectadas pela análise de variância (Tabela 1) entre as espécies vegetais, no que se refere às variáveis morfo-fisiológicas (Tabelas 2 e 3) expressam as características intrínsecas de cada espécie.

As raízes de todas as espécies mostraram lesões radiculares, que foram significativamente mais severas na soja (Tabela 4), única espécie em que houve aumento na severidade das lesões em função da concentração de inóculo (Figura 1).

A multiplicação de $P$. brachyurus foi influenciada pela concentração de inóculo inicial, porém de forma diferenciada entre as espécies vegetais (Tabela 1). Considerando-se a variável NGR, foram observados resultados semelhantes nos dois experimentos, onde a soja $($ NGR $=71,83$ e 854,49$)$ foi significativamente maior que as demais, seguida pelo milho (NGR $=60,61$ e 28,46) (Tabela 5). Considerando-se a média das cinco espécies vegetais, no experimento 1 houve aumento do NGR em função do aumento da densidade de inóculo inicial (Pi) (Figura 3). O maior número de nematoides observados nas raízes de soja poderia, de certa forma, justificar os maiores danos (lesões) observados nas raízes desta espécie.

A multiplicação de $P$. brachyurus foi influenciada pela concentração de inóculo inicial, porém de forma diferenciada entre as espécies vegetais (Tabela 1). Considerando-se a média de todas as espécies vegetais, o fator de reprodução do nematoide foi significativamente maior nas menores concentrações de inóculo (Pi), principalmente no experimento 1 (Figura 2). Estes resultados são semelhantes aos obtidos por Schmitt e Barker (1981) em duas variedades de soja e quatro tipos de solos, em que o FR de P. brachyurus variou de 9,6 a 0,2 quando as plantas foram submetidas às $\mathrm{Pi}_{\mathrm{s}}$ de 110 a 3000 nematoides. 


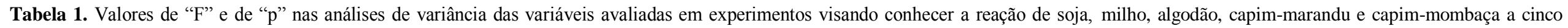
densidade populacional do nematoide Pratylenchus brachyurus.

\begin{tabular}{|c|c|c|c|c|c|c|c|c|c|c|c|c|c|c|c|c|}
\hline \multirow{3}{*}{ TRATAMENTOS } & \multicolumn{16}{|c|}{ VARIÁVEIS } \\
\hline & \multicolumn{8}{|c|}{ EXPERIMENTO 1} & \multicolumn{8}{|c|}{ EXPERIMENTO 2} \\
\hline & ALT & MSECA & MFR & CLORT & FOTO & LESÕES & NGR* & $\mathrm{FR}^{*}$ & ALT & $\begin{array}{l}\text { MSEC } \\
\text { A }\end{array}$ & MFR & CLORT & FOTO & LESÕES & NGR* & $\mathrm{FR}^{*}$ \\
\hline \multirow[t]{2}{*}{$\begin{array}{l}\text { Densidade } \\
\text { populacional(DP) }\end{array}$} & 2,05 & 0,20 & 0,31 & 0,73 & 0,84 & 554,52 & 16,40 & 6,43 & 1,53 & 0,60 & 0,38 & 1,97 & 1,36 & 1421,00 & 3,81 & 154,7 \\
\hline & $\geq 0,05$ & $\geq 0,05$ & $\geq 0,05$ & $\geq 0,05$ & $\geq 0,05$ & $<0,05$ & $<0,05$ & $<0,05$ & $\geq 0,05$ & $\geq 0,05$ & $\geq 0,05$ & $\geq 0,05$ & $\geq 0,05$ & $<0,05$ & $<0,05$ & $<0,05$ \\
\hline \multirow[t]{2}{*}{$\begin{array}{l}\text { Espécies de } \\
\text { plantas (EP) }\end{array}$} & 901,52 & 297,16 & 246,17 & 163,98 & 37,78 & 23,96 & 50,84 & 8,55 & 794,9 & 779,99 & 432,1 & 32,91 & 67,04 & 324,33 & 181,0 & 164,7 \\
\hline & $<0,05$ & $<0,05$ & $<0,05$ & $<0,05$ & $<0,05$ & $<0,05$ & $<0,05$ & $<0,05$ & $<0,05$ & $<0,05$ & $<0,05$ & $<0,05$ & $<0,05$ & $<0,05$ & $<0,05$ & $<0,05$ \\
\hline \multirow[t]{2}{*}{ DP x EP } & 1,35 & 0,49 & 0,22 & 1,48 & 0,34 & 18,04 & 8,83 & 3,58 & 1,18 & 0,64 & 0,83 & 1,37 & 0,68 & 143,50 & 3,41 & 51,17 \\
\hline & $\geq 0,05$ & $\geq 0,05$ & $\geq 0,05$ & $\geq 0,05$ & $\geq 0,05$ & $<0,05$ & $<0,05$ & $<0,05$ & $\geq 0,05$ & $\geq 0,05$ & $\geq 0,05$ & $\geq 0,05$ & $\geq 0,05$ & $<0,05$ & $<0,05$ & $<0,05$ \\
\hline CV. $(\%)$ & 10,35 & 18,24 & 31,95 & 17,17 & 25,38 & 15,38 & 42,18 & 50,77 & 14,66 & 17,75 & 28,67 & 19,46 & 24,30 & 4,79 & 30,17 & 8,80 \\
\hline
\end{tabular}

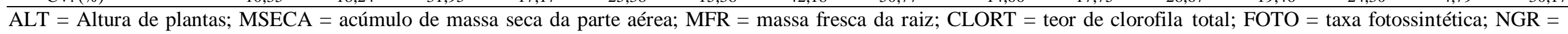
número de nematoides por grama de raiz; $\mathrm{FR}=$ fator de reprodução $(\mathrm{FR})$ do nematoide.

* Dados transformados em $\sqrt{x+0,5}$ para a análise estatística. 
Tabela 2. Altura de plantas, produção de matéria seca da parte aérea, produção de matéria fresca das raízes, teor de clorofila foliar, taxa fotossintética e lesões nas raízes de plantas de soja, algodão, milho, capim-braquiária e capim-mombaça, em função da inoculação com quantidades crescentes do nematoide das lesões radiculares, Pratylenchus brachyurus. Experimento 1.

\begin{tabular}{|c|c|c|c|c|c|c|c|c|c|c|c|}
\hline \multirow{3}{*}{ Espécie } & \multicolumn{5}{|c|}{ Altura de plantas (cm) } & \multirow{3}{*}{ Espécie } & \multicolumn{5}{|c|}{ Matéria seca $(\mathrm{g})$} \\
\hline & \multicolumn{5}{|c|}{ Concentração de inóculo (nematoides/planta) } & & \multicolumn{5}{|c|}{ Concentração de inóculo (nematoides/planta) } \\
\hline & 0 & 333 & 1000 & 3000 & 9000 & & 0 & 333 & 1000 & 3000 & $\begin{array}{l}900 \\
0\end{array}$ \\
\hline Soja & 26,4 & 27,3 & 29,5 & 28,5 & 24,6 & Soja & 9,1 & 9,6 & 10,4 & 9,9 & 9,0 \\
\hline Algodão & 53,3 & 53,9 & 52,6 & 46,6 & 53,0 & Algodão & 36,5 & 36,5 & 34,6 & 32,9 & 37,2 \\
\hline Milho & 111,8 & 118,6 & 117,3 & 114,4 & 124,4 & Milho & 52,9 & 55,0 & 52,2 & 51,9 & 56,2 \\
\hline Mombaça & 106,4 & 109,7 & 113,4 & 112,9 & 113,6 & Mombaça & 30,2 & 29,8 & 32,1 & 32,5 & 30,2 \\
\hline Marandu & 102,5 & 113,2 & 111,8 & 110,6 & 103,7 & Marandu & 38,6 & 40,6 & 40,8 & 39,1 & 37,6 \\
\hline \multirow{3}{*}{ Espécie } & \multicolumn{5}{|c|}{ Matéria fresca da raiz (g) } & \multirow{3}{*}{ Espécie } & \multicolumn{5}{|c|}{ Teor de clorofila $\left(\mathbf{n g} / \mathrm{cm}^{2}\right)$} \\
\hline & \multicolumn{5}{|c|}{ Concentração de inóculo (nematoides/planta) } & & \multicolumn{5}{|c|}{ Concentração de inóculo (nematoides/planta) } \\
\hline & 0 & 333 & 1000 & 3000 & 9000 & & 0 & 333 & 1000 & 3000 & $\begin{array}{l}{ }^{900} \\
0\end{array}$ \\
\hline Soja & 11,6 & 12,7 & 14,8 & 12,9 & 12,4 & Soja & 46,2 & 44,4 & 40,0 & 40,1 & 42,6 \\
\hline Algodão & 17,0 & 16,7 & 16,3 & 16,7 & 16,0 & Algodão & 39,8 & 36,0 & 38,5 & 44,0 & 37,0 \\
\hline Milho & 150,7 & 153,7 & 161,7 & 148,5 & 149,3 & Milho & 16,7 & 16,8 & 17,8 & 18,4 & 18,0 \\
\hline Mombaça & 173,3 & 183,6 & 195,2 & 189,4 & 178,8 & Mombaça & 24,4 & 22,4 & 24,2 & 23,4 & 26,1 \\
\hline Marandu & 162,1 & 145,9 & 158,5 & 146,0 & 158,2 & Marandu & 27,7 & 29,6 & 25,1 & 27,0 & 27,1 \\
\hline \multirow{3}{*}{ Espécie } & \multicolumn{5}{|c|}{ Taxa fotossintética (cm) } & \multirow{3}{*}{ Espécie } & \multicolumn{5}{|c|}{ Lesões nas raízes (Escala 1 a 5 ) } \\
\hline & \multicolumn{5}{|c|}{ Concentração de inóculo (nematoides/planta) } & & \multicolumn{5}{|c|}{ Concentração de inóculo (nematoides/planta) } \\
\hline & 0 & 333 & 1000 & 3000 & 9000 & & 0 & 333 & 1000 & 3000 & $\begin{array}{l}900 \\
0\end{array}$ \\
\hline Soja & 10,2 & 10,8 & 12,4 & 11,2 & 11,4 & Soja & 1 & 2 & 2 & 2 & 3 \\
\hline Algodão & 12,5 & 13,5 & 12,7 & 12,4 & 13,8 & Algodão & 1 & 2 & 2 & 2 & 2 \\
\hline Milho & 15,9 & 18,3 & 17,0 & 16,0 & 17,8 & Milho & 1 & 2 & 2 & 2 & 2 \\
\hline Mombaça & 9,6 & 10,5 & 9,0 & 9,7 & 9,2 & Mombaça & 1 & 2 & 2 & 2 & 2 \\
\hline Marandu & 10,1 & 10,4 & 9,8 & 9,5 & 10,2 & Marandu & 1 & 2 & 2 & 2 & 2 \\
\hline
\end{tabular}


Tabela 3. Altura de plantas, produção de matéria seca da parte aérea, produção de matéria fresca das raízes, teor de clorofila foliar, taxa fotossintética e lesões nas raízes de plantas de soja, algodão, milho, capim-braquiária e capim-mombaça, em função da inoculação com quantidades crescentes do nematoide das lesões radiculares, Pratylenchus brachyurus. Experimento 2.

\begin{tabular}{|c|c|c|c|c|c|}
\hline \multirow{3}{*}{ Espécie } & \multicolumn{5}{|c|}{ Altura de plantas $(\mathrm{cm})$} \\
\hline & \multicolumn{5}{|c|}{ Concentração de inóculo (nematoides/planta) } \\
\hline & 0 & 1500 & 4500 & 13500 & 40500 \\
\hline Soja & 29,6 & 33,8 & 33,8 & 36,9 & 29,7 \\
\hline Algodão & 47,9 & 50,0 & 52,4 & 43,9 & 42,6 \\
\hline Milho & 128,6 & 147,5 & 119,7 & 122,4 & 137,4 \\
\hline Mombaça & 198,5 & 201,9 & 206,5 & 203,3 & 206,3 \\
\hline Marandu & 177,1 & 197,1 & 192,3 & 199,5 & 195,5 \\
\hline \multirow{3}{*}{ Espécie } & \multicolumn{5}{|c|}{ Matéria fresca da raiz $(\mathrm{g})$} \\
\hline & \multicolumn{5}{|c|}{ Concentração de inóculo (nematoides/planta) } \\
\hline & 0 & 1500 & 4500 & 13500 & 40500 \\
\hline Soja & 4,8 & 5,4 & 5,7 & 5,4 & 4,9 \\
\hline Algodão & 12,2 & 8,9 & 9,6 & 9,4 & 9,4 \\
\hline Milho & 105,9 & 101,5 & 86,4 & 106,3 & 118,0 \\
\hline Mombaça & 215,4 & 232,3 & 238,1 & 207,4 & 228,6 \\
\hline Marandu & 186,6 & 173,8 & 178,9 & 162,0 & 162,6 \\
\hline \multirow{3}{*}{ Espécie } & \multicolumn{5}{|c|}{ Taxa fotossintética $(\mathbf{c m})$} \\
\hline & \multicolumn{5}{|c|}{ Concentração de inóculo (nematoides/planta) } \\
\hline & 0 & 1500 & 4500 & 13500 & 40500 \\
\hline Soja & 34,7 & 36,5 & 37,7 & 37,2 & 32,0 \\
\hline Algodão & 20,2 & 22,3 & 20,0 & 22,7 & 20,4 \\
\hline Milho & 23,7 & 25,8 & 24,9 & 23,9 & 22,6 \\
\hline Mombaça & 18,2 & 19,3 & 17,3 & 13,0 & 15,5 \\
\hline Marandu & 19,6 & 18,0 & 21,3 & 19,6 & 18,2 \\
\hline
\end{tabular}

\begin{tabular}{|c|c|c|c|c|c|}
\hline \multirow{3}{*}{ Espécie } & \multicolumn{5}{|c|}{ Matéria seca $(\mathrm{g})$} \\
\hline & \multicolumn{5}{|c|}{ Concentração de inóculo (nematoides/planta) } \\
\hline & 0 & 1500 & 4500 & 13500 & 40500 \\
\hline Soja & 11,2 & 15,4 & 12,2 & 13,8 & 11,2 \\
\hline Algodão & 11,7 & 11,2 & 11,7 & 11,0 & 9,5 \\
\hline Milho & 77,4 & 84,9 & 75,0 & 78,9 & 83,0 \\
\hline Mombaça & 121,6 & 124,3 & 123,1 & 116,5 & 124,4 \\
\hline Marandu & 102,7 & 105,6 & 106,5 & 114,8 & 111,9 \\
\hline \multirow{3}{*}{ Espécie } & \multicolumn{5}{|c|}{ Teor de clorofila $\left(\mathrm{mg} / \mathrm{cm}^{2}\right)$} \\
\hline & \multicolumn{5}{|c|}{ Concentração de inóculo (nematoides/planta) } \\
\hline & 0 & 1500 & 4500 & 13500 & 40500 \\
\hline Soja & 56,3 & 44,1 & 49,8 & 50,7 & 45,9 \\
\hline Algodão & 40,9 & 40,0 & 41,9 & 39,8 & 39,5 \\
\hline Milho & 34,7 & 35,8 & 30,2 & 36,8 & 29,7 \\
\hline Mombaça & 30,2 & 31,9 & 30,9 & 34,6 & 32,5 \\
\hline Marandu & 38,5 & 44,0 & 41,8 & 40,0 & 33,2 \\
\hline \multirow{3}{*}{ Espécie } & \multicolumn{5}{|c|}{ Lesões nas raízes (Escala 1 a 5 ) } \\
\hline & \multicolumn{5}{|c|}{ Concentração de inóculo (nematoides/planta) } \\
\hline & 0 & 1500 & 4500 & 13500 & 40500 \\
\hline Soja & 1 & 2 & 2 & 3 & 4 \\
\hline Algodão & 1 & 2 & 2 & 2 & 2 \\
\hline Milho & 1 & 2 & 2 & 2 & 2 \\
\hline Mombaça & 1 & 2 & 2 & 2 & 2 \\
\hline Marandu & 1 & 2 & 2 & 2 & 2 \\
\hline
\end{tabular}


Inomoto et al. (2001) observaram FRs elevados (2,54 e 7,89) de $P$. brachyurus em duas variedades de algodão inoculadas com 125 e 333 nematoides por planta, os quais decresceram $(0,29$ e 1,81) quando as mesmas variedades foram inoculadas com 27.000 ou 10.125 nematoides. Sendo assim, para efeito de comparação entre as espécies (Tabela 5), utilizou-se os valores de FR de $P$. brachyurus considerando-se as menores $\mathrm{Pi}_{\mathrm{s}}$ (333 e 1500), respectivamente nos experimentos 1 e 2 . Os resultados obtidos no presente trabalho indicam que para avaliação do fator de reprodução de $P$. brachyurus em espécies vegetais deva ser utilizado inóculo com baixa densidade populacional do nematoide. As diferenças observadas nos valores de FR dos dois experimentos podem ser atribuídas ao efeito da menor população inicial $(\mathrm{Pi})$ no experimento 1 $(\mathrm{Pi}=333)$ comparada com a do experimento $2(\mathrm{Pi}=$ 1500) ou a maior temperatura ocorrida no experimento 2.

A ocorrência de sintomas primários (lesões radiculares) decorrentes do parasitismo por $P$. brachyurus indicam que o nematoide é patogênico às cinco espécies vegetais avaliadas, apresentando, contudo, diferentes graus de agressividade, sendo esta mais expressiva na soja (Tabela 4), cultura onde a severidade das lesões aumentou em função da densidade populacional do nematoide (Figura 1). As lesões radiculares, no entanto, não se refletiram em danos de parte aérea em nenhuma das espécies, independente da densidade populacional do nematoide.

Tabela 4. Médias das notas atribuídas às lesões radiculares nas espécies vegetais inoculadas com diferentes densidade populacional de $P$. brachyurus.

\begin{tabular}{lccc}
\hline \multicolumn{1}{c}{ ESPÉCIES } & \multicolumn{2}{c}{ ÍNDICE DE LESÕES } \\
\cline { 2 - 2 } Soja & Experimento 1 & & Experimento 2 \\
\cline { 2 - 2 } Algodoeiro & $2,02 \mathrm{a}$ & & $2,40 \mathrm{a}$ \\
Milho & $1,80 \mathrm{~b}$ & & $1,85 \mathrm{~b}$ \\
Capim-mombaça & $1,80 \mathrm{~b}$ & & $1,80 \mathrm{c}$ \\
Capim-marandu & $1,80 \mathrm{~b}$ & & $1,80 \mathrm{c}$ \\
${(\%)} }$ & 15,38 & \\
\hline
\end{tabular}

Escala de notas: 1 = ausência de lesões 2 = lesões leves (até $25 \%$ de tecido lesionado); $3=$ lesões moderadas (26 a $50 \%$ de tecido lesionado); 4 = lesões severas (51 a $75 \%$ de tecido lesionado); $5=$ lesões muito severas (75 a 100\% de tecido lesionado).

Em experimentos conduzidos em casa-de-vegetação com as culturas de soja (LINDSEY; CAIRNS, 1971) e algodoeiro (INOMOTO et al., 2001; MACHADO et al., 2006), mesmo tendo ocasionado lesões radiculares, $P$. brachyurus não causou danos mensuráveis na parte aérea das plantas inoculadas. Por outro lado, experimentos de campo (DIAS et al., 2010;
EGUNJOBI; LARINDE, 1975; FRANCHINI et al., 2011; SCHMITT; BARKER, 1981) indicam que condições adversas, tais como limitações físicas ou químicas do solo, ou ainda ocorrência de outros patógenos, possam ser condicionantes para que os sintomas nas raízes se reflitam em danos na parte aérea. Sendo assim, práticas de manejo do solo que minimizem o efeito de tais condições podem reduzir os danos associados a P. brachyurus.

O presente experimento foi conduzido em casa-devegetação com temperatura e umidade adequadas e solo devidamente preparado e adubado, fornecendo condições físicas e químicas ideais para o desenvolvimento das plantas. Assim, a ocorrência de sintomas primários nas raízes de soja, algodoeiro, milho, capim-marandu e capim-mombaça causados por P. brachyurus, caracterizados por lesões necróticas, e a ausência de outras condições limitantes ao bom desenvolvimento dessas espécies, não permitiram que estes se refletissem em danos à parte aérea.
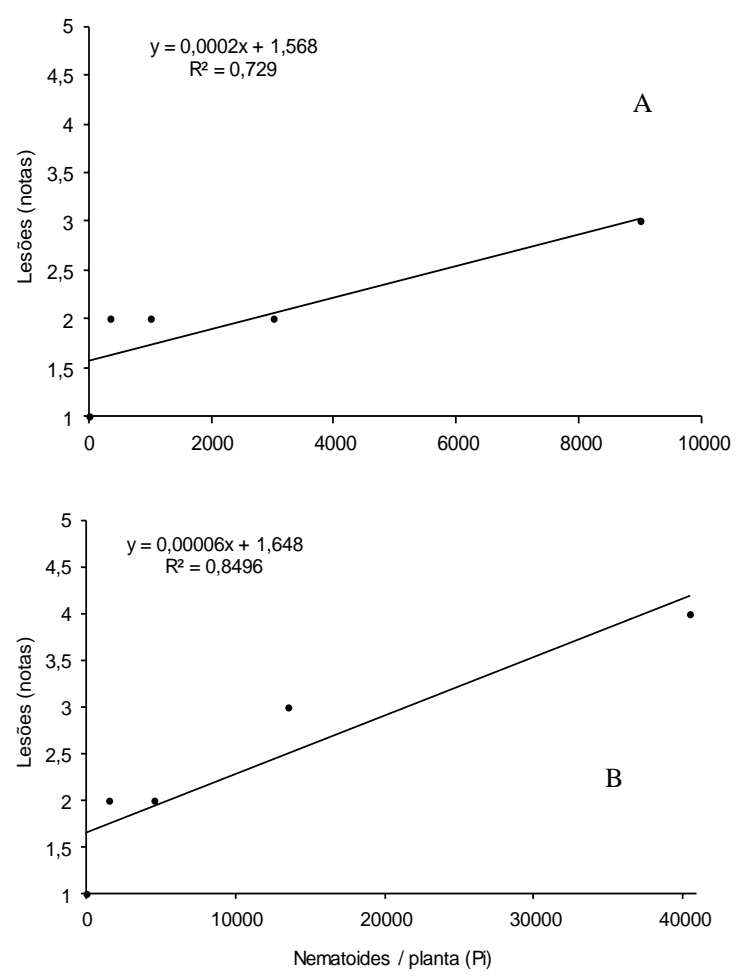

Figura 1. Índice de lesões nas raízes de soja nos experimentos 1 (A) e 2 (B), em função das densidade populacional iniciais de Pratylenchus brachyurus.

São raros os trabalhos que avaliaram o potencial de $P$. brachyurus como causador de danos em milho, prevalecendo o conceito que a cultura, embora hospedeira favorável (INOMOTO, 2011), apresenta alta tolerância ao nematoide. Em experimento estabelecido em microparcelas para avaliar o efeito de adição de material orgânico ao solo sobre os danos de $P$. brachyurus ao milho, Egunjobi e Larinde (1975) 
verificaram correlação positiva $(r=0,66)$ entre a densidade populacional do nematoide nas raízes e a produtividade, sugerindo que, mesmo em altas populações nas raízes, os danos do nematoide foram limitados pelas ótimas condições de fertilidade obtida pela adição do material orgânico ao solo. Resultados semelhantes foram obtidos com o capim-marandu ( $B$. brizantha) que, mesmo sendo suscetível a $P$. brachyurus (DIAS-ARIEIRA et al., 2009; INOMOTO et al., 2007), não demostrou danos em função do parasitismo (CARVALHO et al., 2013).

As variáveis nematoides por grama de raiz (NGR) e fator de reprodução (FR) tem sido utilizadas para caracterizar a reação (resistência ou suscetibilidade) de plantas a fitonematoides. Em ambos experimentos, o milho mostrou-se uma espécie boa hospedeira de $P$. brachyurus (FR de 25,17 e 1,80), sendo a espécie que apresentou o maior FR no experimento 1, confirmando os resultados de Inomoto (2011). Na densidade populacional de 1.500 nematoides/planta (experimento 2) o FR da soja $(F R=2,67)$ foi superior aos demais, sendo seguido pelo milho $(\mathrm{FR}=1,80)$. $\mathrm{O}$ algodão apresentou FR $<1$ em ambos os experimentos na densidade populacional de 333 e 1.500 nematoides/planta (Tabela 5).

Tabela 5. Número de nematoides por grama de raiz (NGR) e fator de reprodução (FR) de $P$. brachyurus nas espécies vegetais inoculadas com 333 (experimento 1) ou 1.500 (experimento 2) espécimes / planta.

\begin{tabular}{lccccc}
\hline ESPECIES & \multicolumn{2}{c}{ NGR } & & \multicolumn{2}{c}{ FR } \\
\cline { 2 - 3 } \cline { 5 - 6 } & Exp. 1 & Exp. 2 & & Exp. 1 & Exp. 2 \\
\cline { 2 - 3 } \cline { 5 - 6 } Soja & $71,83 \mathrm{a}$ & $854,49 \mathrm{a}$ & & $2,47 \mathrm{~b}$ & $2,67 \mathrm{a}$ \\
Algodoeiro & $7,27 \mathrm{~b}$ & $12,43 \mathrm{~b}$ & & $0,33 \mathrm{~b}$ & $0,07 \mathrm{c}$ \\
Milho & $60,61 \mathrm{~b}$ & $28,46 \mathrm{~b}$ & & $25,17 \mathrm{a}$ & $1,80 \mathrm{~b}$ \\
Mombaça & $7,27 \mathrm{~b}$ & $0,53 \mathrm{~b}$ & & $1,42 \mathrm{~b}$ & $0,08 \mathrm{c}$ \\
Marandu & $8,48 \mathrm{~b}$ & $2,37 \mathrm{~b}$ & & $2,87 \mathrm{~b}$ & $0,25 \mathrm{c}$ \\
${$\cline { 1 - 2 }$(\%)} }$ & 48,97 & 31,79 & & 59,53 & 8,04
\end{tabular}

Dados originais, médias de oito repetições; valores seguidos de mesma letra nas colunas não diferem significativamente pelo teste de Duncan $(\mathrm{p} \leq 0,05)$. *Para efeito de análise estatística os dados foram transformados para $\sqrt{x+0,5}$

A alta multiplicação de $P$. brachyurus em milho pode explicar, de certa forma, o crescimento da ocorrência do nematoide em alta densidade populacional no Brasil Central. Nos últimos anos, houve expressivo aumento da área cultivada com milho imediatamente após a cultura da soja (milho safrinha), em sistema plantio direto. $\mathrm{O}$ reduzido tempo entre a colheita da soja e o estabelecimento do milho, sem revolvimento do solo, permitiria a migração dos nematoides hospedados nas raízes de soja - ainda não apodrecidas - para as raízes do milho, resultando em intensa multiplicação.
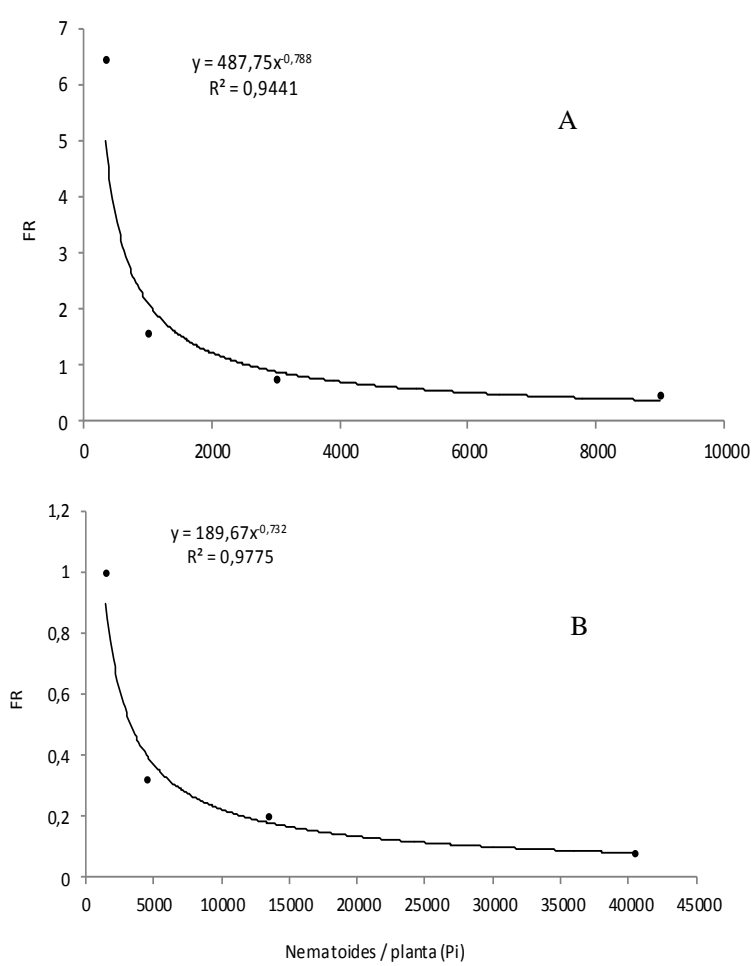

Figura 2. Valores médios dos fatores de reprodução (FR) do nematoide das lesões radiculares em soja, algodoeiro, milho, capim-marandu e capim-mombaça nos experimentos 1 (A) e 2 (B), em função das densidade populacional iniciais de $P$. brachyurus.
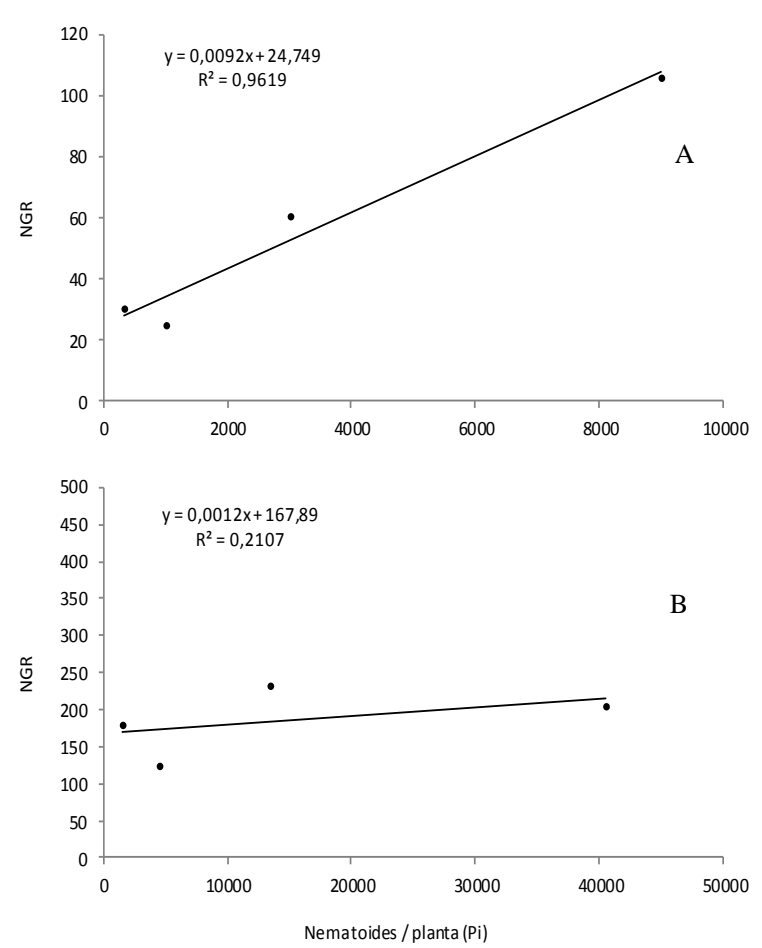

Figura 3. Valores médios do número de nematoides das lesões radiculares por grama de raízes (NGR) em soja, algodoeiro, milho, capim-marandu e capim-mombaça nos experimentos 1 (A) e 2 (B), em função das densidade populacional iniciais de $P$. brachyurus. 
Os dados de FR obtidos em capim-marandu, embora com expressiva variação em função do experimento (2,87 e 0,25), indicam suscetibilidade ao nematoide. Valor muito próximo $(\mathrm{FR}=2,0)$ foi obtido por DiasArieira et al. (2009) em cultivar não especificada de capim-braquiária (B. brizantha), o que permite supor que o uso por longos períodos dessa forrageira em rotações ou sucessões à soja poderia se constituir em fator de risco ao cultivo para culturas subsequentes.

Os valores de FR obtidos em capim-mombaça (1,42 e 0,08 ) são conflitantes com a literatura (INOMOTO et al., 2007), que caracterizam a espécie em questão como boa hospedeira do nematoide. Em função disso, sugerese que trabalhos adicionais com essa espécie sejam realizados.

Os dados obtidos nos dois experimentos evidenciaram a suscetibilidade da cultura da soja à presença de P. brachyurus, embora os valores dos FRs (2,47 e 2,67 nas menores $\mathrm{Pi}_{\mathrm{s}}$ nos experimentos 1 e 2) estejam muito abaixo dos encontrados em outros trabalhos (ACOSTA; MALEK, 1979; SCHMITT; BARKER, 1981) o que pode ser atribuído à variedade utilizada ou às condições experimentais. A suscetibilidade de algodoeiro a $P$. brachyurus é tema de discussão. Nos dois experimentos, os FRs variaram entre 0,33 e 0,07 (experimentos 1 e 2, respectivamente). No entanto, em outros trabalhos (GOULART et al., 1997; MACHADO et al. ,2007), dependendo da cultivar os valores de FR variaram entre 0,26 e 23,2.

\section{Conclusões}

O nematoide das lesões radiculares, $P$. brachyurus, causa sintomas primários (lesões radiculares) em soja, algodoeiro, milho, capim-marandu e capim-mombaça;

Das espécies testadas, a soja apresenta sintomas de lesões radiculares mais severos, e mais intensos ainda quando a cultura é submetida a maior densidade populacional do nematoide;

$\mathrm{O}$ nematoide das lesões é pouco agressivo às culturas de soja, milho, algodão, capim-braquiária e capim-mombaça;

Dentre as espécies vegetais avaliadas, milho e soja são as que permitem maior multiplicação do nematoide das lesões.

\section{Referências Bibliográficas}

ABREU, A. B. de L.; AGNES, D. C. Nematoides: amostragem, armazenamento e transporte de amostras. sojamilho, safra 2014/2015, Pesquisa, Tecnologia, Produtividade, Chapadão do Sul-MS, p. 109-110, 2014. Disponível em: <http://www.fundacaochapadao.com.br/publicacoes/>. Acesso em: 21 dez. 2015.
ACOSTA, N.; MALEK, R. B. Influence of temperature on population development of eight species of Pratylenchus on soybean. Journal of Nematology, Loudonville, v. 11, n. 3, p. 229-232, 1979.

CARVALHO, C.; FERNANDES, C. D.; SANTOS, J. M.; MACEDO, M. C. M. Densidade populacional de Pratylenchus spp. em pastagens de Brachiaria spp. e sua influência na disponibilidade e na qualidade da forragem. Revista Ceres, Viçosa-MG, v. 60, n. 1, p. 30-37, 2013.

COOLEN, W. A.; D'HERDE, C. J. A method for the quantitative extraction of nematodes from plant tissue. State Nematology and Entomology Research Station, Ghent, 77 p, 1972.

DIAS, W. P.; ASMUS, G. L.; SILVA, J. F. V.; GARCIA, A.; CARNEIRO, G. E. S. 2010. Nematoides. In: ALMEIDA, A. M. R; SEIXAS, C. D. S. (ed). Soja: doenças radiculares e de hastes e inter-relações com o manejo do solo e da cultura. , Londrina-PR: Embrapa Soja, 2010. p. 173-206.

DIAS-ARIEIRA, C. R.; FERRAZ, S.; RIBEIRO, R. C. F. Reação de gramíneas forrageiras a Pratylenchus brachyurus. Nematologia Brasileira, Piracicaba-SP, v. 33, n. 1, p. 90-93, 2009.

EGUNJOBI, O. A.; LARINDE, M. A. Nematodes and maize growth in Nigeria. II. Effects of some amendments on populations of Pratylenchus brachyurus and on the growth and production of maize (Zea mays) in Nigeria. Nematologia Mediterranea, Bari, v. 3, n. 1, p. 65-73, 1975.

FRANCHINI, J. C.; DEBIASI, H.; DIAS, W. P. Variabilidade espacial de atributos químicos do solo e da população de Pratylenchus brachyurus. In: INAMASU, R. Y.; NAIME, J. de M.; RESENDE, A. V.; BASSOI, L. H.; BERNARDI, A. C. de C. (Org.). Agricultura de precisão: um novo olhar. $1^{\text {a }}$ ed. São Carlos: Embrapa Instrumentação Agropecuária, 2011, p. $157-161$.

GHINI, R. Coletor Solar para Desinfestação de Substratos para Produção de Mudas Sadias. Jaguariúna-SP: Embrapa Meio Ambiente, 2004. 5p. (Circular Técnica 4).

GOULART, A. M. C.; INOMOTO, M. M.; MONTEIRO, A. R. Hospedabilidade de oito cultivares de algodoeiro a Pratylenchus brachyurus. Nematologia Brasileira, Piracicaba-SP, v. 21, n. 2, p. 111-118, 1997.

INOMOTO, M. M. Avaliação da resistência de 12 híbridos de milho a Pratylenchus brachyurus. Tropical Plant Pathology, Viçosa-MG, v. 36, n. 5, p. 308-312, 2011.

INOMOTO, M. M.; MACHADO, A. C. Z.; ANTEDOMÊNICO S. R. Reação de Brachiaria spp. e Panicum maximum a Pratylenchus brachyurus. Fitopatologia Brasileira, Brasília-DF, v. 32, n. 4, p. 341-344, 2007.

INOMOTO, M. M.; GOULART, A. M. C.; MACHADO, A. C. Z.; MONTEIRO, A. R. Effect of population densities of Pratylenchus brachyurus on the growth of cotton plants. Fitopatologia Brasileira, Brasília-DF, v. 26, n. 2, p. 192-196, 2001.

LINDSEY, D. W.; CAIRNS, E. J. Pathogenicity of the lesion nematode, Pratylenchus brachyurus, on six soybean cultivars. 
Journal of Nematology, Loudonville, v. 3, n. 3, p. 220-226, 1971.

MACHADO, A. C. Z.; BELUTI, D. B.; SILVA, R. A.; SERRANO, M. A. S.; INOMOTO, M. M. Avaliação de danos causados por Pratylenchus brachyurus em algodoeiro. Fitopatologia Brasileira, Brasília-DF, v. 31, n. 1, p. 11-16, 2006.

MACHADO, A. C. Z.; FERRAZ, L. C. C. B.; INOMOTO, M. M. Response of cotton cultivars to two brazilian populations of Pratylenchus brachyurus (Godfrey) Filipjev \& Sch. Stehk. Journal of Cotton Science, Baton Rouge, v. 11, p. 288-292, 2007.

OOSTENBRINK, M. Major characteristics of the relation between nematodes and plants. Mededelingen Landbouwhogeschool, Wageningen, v. 66, p. 3-46, 1966.

RIBEIRO, N. R.; DIAS, W. P.; SANTOS, J. M. Distribuição de fitonematoides em regiões produtoras de soja do estado de Mato Grosso. Rondonópolis-MT: Fundação MT, 2010. p. 289-296. (Boletim de Pesquisa de Soja).
SASSER, J. N.; FRECKMAN, D. W. A world perspective on nematology: The hole of the society. In: VEECH, J.A. \& D.W. DICKSON (ed). Vistas on Nematology, Hyattsville: Society of Nematologists, 1987. p. 7-14.

SILVA, R. A.; SERRANO, M. A.; GOMES, A. C.; BORGES, D. C.; SOUZA, A. A.; ASMUS, G. L.; INOMOTO, M. M. Ocorrência de Pratylenchus brachyurus e Meloidogyne: incognita na cultura do algodoeiro no estado do Mato Grosso. Fitopatologia Brasileira, Brasília-DF, v. 29, n. 3, p. 337, 2004.

SCHMITT, D. P.; BARKER, K. R. Damage and reproductive potentials of Pratylenchus brachyurus and P. penetrans on soybean. Journal of Nematology, Loudonville v. 13, n. 3, p. 327-332, 1981. 